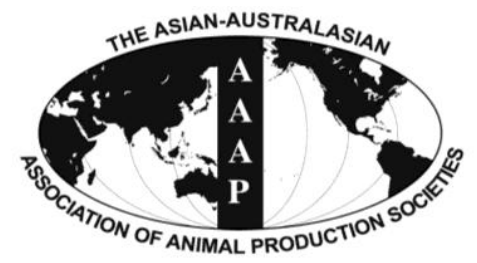

Asian Australas. J. Anim. Sci.

Vol. 26, No. 7 : 916-920 July 2013

http://dx.doi.org/10.5713/ajas.2013.13108

www.ajas.info

pISSN $1011-2367$ elSSN 1976-5517

\title{
Development of Genetic Markers for Triploid Verification of the Pacific Oyster, Crassostrea gigas
}

\author{
Jung-Ha Kang, Hyun Jeong Lim ${ }^{1}$, Hyun-Soek Kang, Jung-Mee Lee², Sumy Baby ${ }^{3}$, and Jong-Joo Kim** \\ Biotechnology Research Division, NFRDI, Busan 619-705, Korea
}

\begin{abstract}
The triploid Pacific oyster, which is produced by mating tetraploid and diploid oysters, is favored by the aquaculture industry because of its better flavor and firmer texture, particularly during the summer. However, tetraploid oyster production is not feasible in all oysters; the development of tetraploid oysters is ongoing in some oyster species. Thus, a method for ploidy verification is necessary for this endeavor, in addition to ploidy verification in aquaculture farms and in the natural environment. In this study, a method for ploidy verification of triploid and diploid oysters was developed using multiplex polymerase chain reaction (PCR) panels containing primers for molecular microsatellite markers. Two microsatellite multiplex PCR panels consisting of three markers each were developed using previously developed microsatellite markers that were optimized for performance. Both panels were able to verify the ploidy levels of 30 triploid oysters with $100 \%$ accuracy, illustrating the utility of microsatellite markers as a tool for verifying the ploidy of individual oysters. (Key Words: Triploid, Oyster, Microsatellite, Multiplex PCR)
\end{abstract}

\section{INTRODUCTION}

Economically beneficial characteristics of polyploidy have led to triploid organisms being used in a wide range of farming systems, notably in bivalve mollusks (Beaumont and Fair-brother, 1991; Nell, 2002; Piferrer et al., 2009). The production of tetraploid oysters (Guo and Allen 1994b; Guo et al., 1996; McCombie et al., 2005b) led to a great increase in the aquaculture of triploid oysters produced by mating a tetraploid oyster with diploid parents (Guo et al., 1996). Tetraploid $\times$ diploid crosses provide higher yields of triploid oysters, which leads to an overall expansion of triploid oysters in the shellfish industry and thus in the environment.

Allen and Downing (1986) reported that consumers prefer triploid oysters over diploid oysters in the summer due to their better flavor and firmer texture. During the warm summer months, diploid oysters undergo sexual

\footnotetext{
* Corresponding Author: Jong-Joo Kim. Tel: +82-53-810-3027, Fax: +82-53-801-3027, E-mail: kimjj@ynu.ac.kr

${ }^{1}$ West Sea Fisheries Research Institute, NFRDI, Incheon 400-420, Korea.

2 Gyeongsangnam-do Fisheries Resources Research Institute, Tongyoung 650-974, Korea.

3 School of Biotechnology, Yeungnam University, Gyeongsan 712-749, Korea.

Submitted Jan. 19, 2013; Accepted Apr. 2, 2013; Revised Apr. 6, 2013
}

maturation using energy from glycogen reserves to produce gametes. As a way to counteract the decline in summer sales, "sterile" triploid oysters are being produced. While diploid oysters use their glycogen stores to produce gametes, triploid oysters retain their glycogen, allowing them to focus on growth instead of reproduction. Although triploid oysters are not sterile, they have severely reduced fecundity with little or no potential of spawning. As a result, triploid oysters reach market size faster than diploids, are larger in size than diploids of similar age, and retain their flavor and consistency during summer months.

Triploidy in mollusks is induced by suppressing the formation of either the first or second polar body by treating with heat, pressure, or chemical shock (Beaumont and Fairbrother, 1991). After attempts by many researchers, Guo and Allen (1994c) successfully produced tetraploid Pacific oysters, Crassostrea giga, by blocking the first polar body in the eggs of triploids with cytochalasin B treatment. Although the resulting triploid had reduced reproductive ability, they could still produce fertile gametes. There have been many attempts to produce tetraploid oysters in an effort to overcome the supply limitation caused by the tetraploid production patent. Thus, it is important to develop a method to verify the ploidy level of organisms after induction or to detect polyploidy in the environment where oyster farming has occurred for long periods of time.

Various methods (e.g., flow cytometry, karyotyping, and 
particle size analysis) have been used to confirm ploidy. Flow cytometry, in which the ploidy level and DNA contents of cells are compared to a known control, has been the preferred direct method for triploid verification in oysters because hundreds of samples can be analyzed at the same time and the relative percentage of triploid induction can also be analyzed (Harrell et al., 1995). However, this method provides only an approximate estimation of the ploidy level and measuring cellular DNA content is not only time consuming, but also costly and labor intensive. Red blood cell size analysis and karyotyping provide the most straightforward information about the ploidy level, but they are also time consuming and labor intensive. Several other methods exist to determine ploidy level, including image analysis (Ge'rard et al., 1994a), microfluorometry (Durand et al., 1990) and nuclear sizing (Gardner et al., 1996).

Another direct method of triploidy verification is the use of polymorphic DNA markers, such as microsatellites (Slabbert et al., 2010). Microsatellites, or simple sequence repeats (SSRs), are highly polymorphic, multi-allelic, codominant, reproducible, and easy to interpret molecular markers that have been used to determine individual genetic variability and to study the genetic structure of a population (Alam et al., 2012; Dadi et al., 2012a; Dadi et al., 2012b). The usefulness of the molecular markers relies on locus heterozygosity within the female and on the allele inherited from a male of a different size than those of the two female alleles. A large number of loci are required to reliably identify triploidy, which is now possible in C. gigas, as a large number of microsatellite markers are available (Magoulas et al., 1998; Li et al., 2003; Sekino et al., 2003). In this study, we tested 30 previously developed polymorphic microsatellite loci and selected six of them for their application to ploidy verification of $C$. gigas. The development of an accurate protocol for triploidy verification of $C$. gigas using appropriate polymorphic microsatellite markers and their multiplex PCR was analyzed in this study.

\section{MATERIAL AND METHODS}

\section{Sample collection}

A total of 30 triploid oysters from a commercial oyster farm located on the western coast of the Korean Peninsula were collected, in addition to 96 diploid oysters from of each the western and southern coasts of the Korean Peninsula. Mantle tissue samples were preserved in $100 \%$ ethanol at the sampling site, and then samples were transported to the laboratory for DNA extraction. Total DNA was isolated from each sample using a MagExtractor MFX-6100 automated DNA extraction system (Toyobo, Osaka, Japan). The extracted genomic DNA was quantified using a Nanodrop ND-1000 spectrophotometer (Thermo
Fisher Scientific, Barrington, IL, USA) and stored at $-20^{\circ} \mathrm{C}$ until microsatellite genotyping analysis.

\section{Initial genotyping}

Thirty microsatellite markers were selected from two previous reports (Magoulas et al., 1998; Li et al., 2003) based on allele number and annealing temperature. Among these, 11 that showed clear PCR products without the indication of a null allele were selected, which are listed in Table 1. PCR amplification was performed in a $10 \mu \mathrm{l}$ reaction mixture containing $0.25 \mathrm{U}$ Ex taq DNA polymerase (TaKaRa Biomedical Inc., Shiga, Japan), 1× PCR buffer, $0.2 \mathrm{mM}$ dNTP mix, $10 \mathrm{pmol}$ of each primer (forward primer of each pair was 5'-end-labeled with 6-FAM, NED, and HEX dyes; PE Applied Biosystems, Boston), and $100 \mathrm{ng}$ template DNA, using a PTC 200 DNA Engine (MJ Research, Waltham, MA, USA). PCR conditions were as follows: $11 \mathrm{~min}$ at $95^{\circ} \mathrm{C}$, followed by 35 cycles of $1 \mathrm{~min}$ at $94^{\circ} \mathrm{C}, 1 \mathrm{~min}$ at the annealing temperature listed in Table 1 , and $1 \mathrm{~min}$ at $72^{\circ} \mathrm{C}$, with a final extension of $5 \mathrm{~min}$ at $72^{\circ} \mathrm{C}$. Microsatellite polymorphisms were screened using an $\mathrm{ABI}$ PRISM 3130 XL automated DNA sequencer (Applied Biosystems, Boston), and alleles were designated according to PCR product size, relative to a molecular size marker (GENESCAN 400 HD [ROX]; PE Applied Biosystems, Boston).

\section{Multiplex PCR protocol}

After initial amplification, six polymorphic dinucleotide microsatellites were selected based on the observed heterozygosity and PCR product size to ensure clear separation, and grouped into two panels based on the size range of the PCR products for multiplex PCR. Panel 1 included the loci, ucdCg170, $\mathrm{Cg} 108, \mathrm{Cg} 49$, which produced PCR products of 89 base pairs (bp) to $201 \mathrm{bp}$. Panel 2 included the loci, ucdCg129, ucdCg186, and ucdCg151, which produced PCR products of 204 to $326 \mathrm{bp}$. Panel III was made by mixing all of the primers for the six loci. Forward primers for each locus were labeled with different dyes: ucdCg170 and ucdCg129 were labeled with NED; Cg108 and ucdCg186 were labeled with HEX; and Cg49 and ucdCg151 were labeled with FAM (Applied Biosystems, Foster City, CA, USA). The annealing temperature and the primer concentration in each panel were optimized and are summarized in Table 2.

\section{RESULTS AND DISCUSSION}

A rapid and cost-effective detection tool for triploid verification was developed for the Pacific oyster, C. gigas, using previously identified microsatellite markers. This method can be used for future application to the development of triploid oysters and the monitoring of 
Table 1. Microsatellite loci tested in this study. Those used for multiplex PCR are shown emboldened

\begin{tabular}{|c|c|c|c|c|c|c|c|}
\hline Locus & Primer sequence $\left(5^{\prime}-3^{\prime}\right)$ & $\begin{array}{l}\mathrm{AT} \\
\left({ }^{\circ} \mathrm{C}\right)\end{array}$ & $\mathrm{Na}$ & Ho & $\mathrm{He}$ & $\begin{array}{c}\mathrm{RCR} \\
\text { range (bp) }\end{array}$ & $\begin{array}{c}\text { GenBank } \\
\text { accession no. }\end{array}$ \\
\hline $\mathrm{Cg} 108$ & $\begin{array}{l}\text { F: 6FAM ATATGTAATGATTACGAAACTC } \\
\text { R: GTATGAGATTTGGTTCCACC }\end{array}$ & 58 & 39 & 0.847 & 0.953 & $89-187$ & Y12087 \\
\hline CGE009 & $\begin{array}{l}\text { F: NED TTCGTTGAAGGTGACAAGTG } \\
\text { R: GCATTTTGGGATGAACAGA }\end{array}$ & 52 & 16 & 0.736 & 0.782 & $90-136$ & CX068958 \\
\hline ucdCg170 & $\begin{array}{l}\text { F: NED TGGTGGTCAGTGAATGTGAGA } \\
\text { R: CGGACAGTAGCCTTTTAACACA }\end{array}$ & 58 & 35 & 0.852 & 0.935 & $98-186$ & AF468568 \\
\hline $\mathrm{Cg} 49$ & $\begin{array}{l}\text { F: HEX CATCAGGGGTAAATTAAAGTAAGC } \\
\text { R: CCACAGACGATTTCATATATCCTG }\end{array}$ & 58 & 30 & 0.699 & 0.923 & $121-201$ & Y12086 \\
\hline ucdCg109 & $\begin{array}{l}\text { F: NED GCTATGGTTGTCATCCTCGAA } \\
\text { R: TGCCTTTATCGGTTTTGCTT }\end{array}$ & 53 & 39 & 0.911 & 0.957 & $130-250$ & AF468525 \\
\hline ucdCg198 & $\begin{array}{l}\text { F: HEX GAAAGACACGACCGGAGAGA } \\
\text { R: CTGATGATGTCCCACACCTG }\end{array}$ & 58 & 31 & 0.797 & 0.881 & $199-291$ & AF468596 \\
\hline ucdCg181 & $\begin{array}{l}\text { F: HEX CACCCCAAAGGACCACATAC } \\
\text { R: TGTCAGCATGGGTAAGTCCA }\end{array}$ & 58 & 36 & 0.89 & 0.941 & 204-294 & AF468579 \\
\hline ucdCg129 & $\begin{array}{l}\text { F: NED CGAATTTTTCGGACATCGTT } \\
\text { R: GTGGTATGCCTGCATCATGT }\end{array}$ & 58 & 31 & 0.724 & 0.941 & $204-274$ & AF468534 \\
\hline CGE005 & $\begin{array}{l}\text { F: 6FAM AAAGATGAATGGTTGGGAG } \\
\text { R: AATTAAGGAAAACGGATGC }\end{array}$ & 52 & 15 & 0.678 & 0.739 & $213-259$ & BQ426816 \\
\hline ucdCg186 & $\begin{array}{l}\text { F: HEX GCCGCCGATTCTCTTAGATT } \\
\text { R: GGGCTAGCTAGTCATCACCCTA }\end{array}$ & 58 & 30 & 0.827 & 0.946 & $229-301$ & AF468584 \\
\hline ucdCg151 & $\begin{array}{l}\text { F: 6FAM AGGTAATCCGCAAACCAGTG } \\
\text { R: GCATTGCGTCAGGATTAGGT }\end{array}$ & 58 & 31 & 0.901 & 0.925 & $248-326$ & AF468553 \\
\hline
\end{tabular}

triploid oysters in nature and in aquatic farms. As reported by the developers (Magoulas et al., 1998; Li et al., 2003), all 11 microsatellites were polymorphic in 384 diploid individuals. Similarly, triploid individuals clearly showed three alleles at all loci.

Among the 11 microsatellite markers tested, we selected six with primer sets of the same annealing temperature and on the basis of their expected heterozygosity values, which ranged from 0.71 to 0.86 and were similar to the values suggested by Slabbert et al. (2010). These primers were polymorphic in all of the 192 diploid individuals from two wild populations and had allele numbers ranging from 30 to 39, which was much greater than the original reports, probably due to the large sample in this study. These six primer sets were grouped into two panels of three primers for easy labeling with the most common fluorescent dyes i.e., NED, HEX, and FAM, and for producing PCR products that could be clearly separated during analysis: Panel I, ucdCg170, Cg108, and Cg49 loci; and Panel II for ucdCg129, ucdCg186, and ucdCg151 loci. For each panel, each primer concentration and annealing temperature were adjusted as shown in Table 2 so that the peaks from each

Table 2. Multiplex PCR panels condition and the number of individuals with 3 alleles genotype in the triploid controls

\begin{tabular}{|c|c|c|c|c|c|c|c|c|c|c|}
\hline \multirow{2}{*}{ Panel } & \multirow{2}{*}{ Primers } & \multirow{2}{*}{$\begin{array}{l}\text { Primer conc. } \\
(\mathrm{pmol} / \mu \mathrm{l})\end{array}$} & \multirow{2}{*}{$\begin{array}{l}\text { AT } \\
\left({ }^{\circ} \mathrm{C}\right)\end{array}$} & \multirow{2}{*}{$\begin{array}{c}\text { PCR range } \\
\text { (bp) }\end{array}$} & \multicolumn{6}{|c|}{ Number of individuals with 3 alleles at 6 loci } \\
\hline & & & & & 1 & 2 & 3 & 4 & 5 & 6 \\
\hline \multirow[t]{3}{*}{$\overline{\mathrm{I}}$} & ucdCg170 & 0.30 & 58 & $89-201$ & 4 & 23 & 3 & - & - & - \\
\hline & Cg108 & 0.50 & & & $(13.3 \%)$ & $(76.7 \%)$ & $(10 \%)$ & & & \\
\hline & $\mathrm{Cg} 49$ & 0.30 & & & & & & & & \\
\hline \multirow[t]{3}{*}{ II } & ucdCg129 & 0.20 & 58 & $204-326$ & 9 & 16 & 5 & - & - & - \\
\hline & ucdCg186 & 0.20 & & & $(30 \%)$ & $(53.3)$ & $(16.7)$ & & & \\
\hline & ucdCg151 & 0.30 & & & & & & & & \\
\hline \multirow[t]{6}{*}{ III } & ucdCg170 & 0.20 & 56 & $89-326$ & 0 & 1 & 5 & 13 & 10 & 1 \\
\hline & $\mathrm{Cg} 108$ & 0.50 & & & & $(3.3 \%)$ & $(16.7 \%)$ & $(43.3 \%)$ & $(33.3 \%)$ & $(3.3 \%)$ \\
\hline & $\mathrm{Cg} 49$ & 0.20 & & & & & & & & \\
\hline & ucdCg129 & 0.25 & & & & & & & & \\
\hline & ucdCg186 & 0.15 & & & & & & & & \\
\hline & ucdCg151 & 0.20 & & & & & & & & \\
\hline
\end{tabular}


primer set showed the same level of amplification. Using these two test panels, all 30 individuals from a commercial oyster farm were verified as triploid. An example of a genotyping electropherogram of a diploid and triploid individual with these two panels is shown in Figure 1. To confirm the results obtained in our multiplex PCRs, all of the genotypes were compared to those generated in single PCR reactions, which showed identical results in all of the tested samples. In the panel testing of the 30 individuals, the majority showed three alleles on at least two loci, 23 (76.7\%) and 16 (53.3\%) in Panels I and II, respectively. In Panel III, which included six primers, only one of the 30 individuals had three alleles at all of the six loci and the major group (13 individuals, 43.3\%) had three alleles at three loci (Table 2).

To develop successful molecular markers for ploidy identification, a large number of loci must be tested in combination(Chambers and MacAvo, 2000). These primers can be prepared in multiplex PCR reactions to reduce costs and to increase data per reaction, making it cheaper and more rapid compared to single-locus PCR reactions. Increasing the number of primers in the multiplex can increase the accuracy of the analysis, but also can increase the ambiguity if the sizes of PCR products from different loci are similar. Thus, the number of primers in the multiplex should be chosen so that a clear result can be obtained with a minimum number of primer sets. To verify triploid abalones, Slabbert et al. (2010) screened 30 microsatellite makers and developed a microsatellite multiplex PCR consisting of seven markers. In our study, two multiplex panels of three primers each resulted in $100 \%$ ploidy verification. These two panels were composed of three primer sets with different PCR product sizes. Because one locus with three alleles is enough for ploidy verification, either one of the panels should be sufficient for ploidy verification; the second panel can be used to clarify any ambiguous results. Another panel composed of all six primer sets could also be produced because primers labeled with the same fluorescent dye in different panels produce non-overlapping PCR products. This will reduce the time and cost for ploidy verification with desired accuracy.

Triploid shellfish improved meat quality and superior growth when the increase in body size ranges from $30 \%$ to $40 \%$ in most species; in some species an increase in body size of up to 50 to $70 \%$ is acceptable (Guo, 1999; Guo and Allen, 1994a). Because of triploid gigantism, triploids have been developed in many aquaculture mollusk species. Although triploids have been developed in several oyster species, including Eastern oysters, C. virginica, Sydney rock oysters, Saccostrea glomerata, and European flat oysters Ostrea Edulis, triploid oysters are only commercially produced for the Pacific oyster by mating tetraploid and diploid oysters (Guo et al., 1996; Nell, 2002). However, tetraploid oyster production is not feasible in all oysters; tetraploid oyster production was unsuccessful in species such as the Sydney rock oyster (Nell, 2002). Therefore, application of the methods described in this study can be applied to the future development of triploid oysters and mollusks.

Our results demonstrate the utility of microsatellite

\section{Panel I}
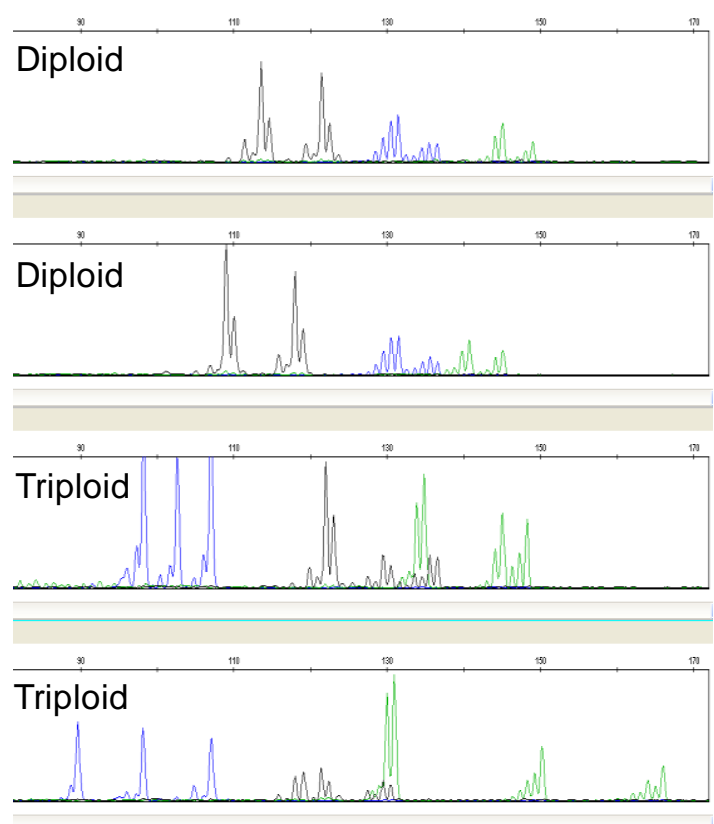

\section{Panel II}

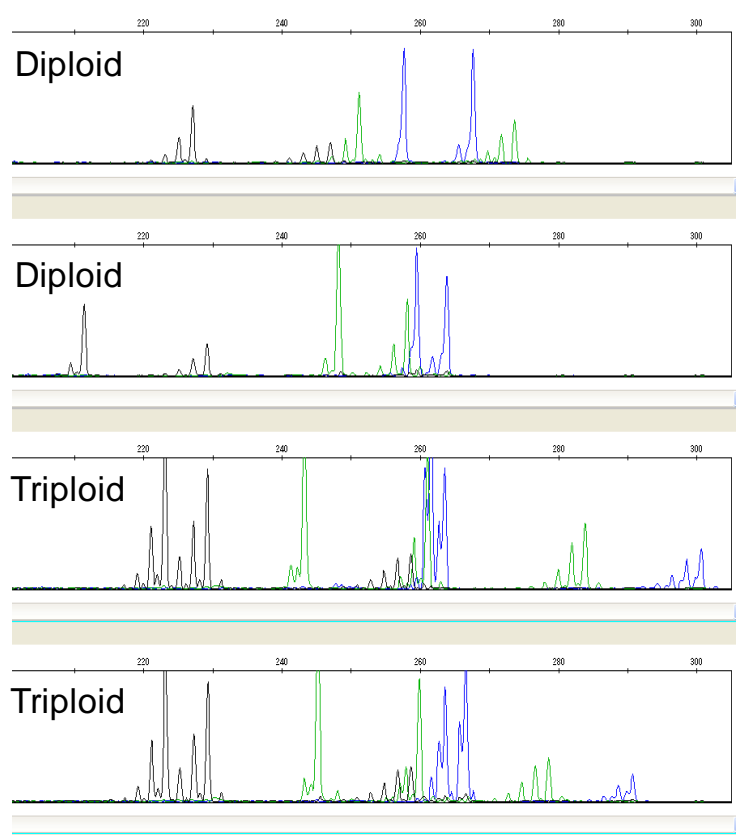

Figure 1. Electropherograms showing the alleles of each of the six loci (panel I and panel II). 
markers as a tool for verifying the ploidy of individual oysters. Individual ploidy verification can be performed quickly and regularly and could facilitate ploidy investigation. Furthermore, this method could help to determine whether oysters revert from the triploid state to the diploid state over time or during the development of triploid oysters by other techniques.

\section{ACKNOWLEDGEMENTS}

This work was supported by grants from the National Fisheries Research and Development Institute (NFRDI) in Korea.

\section{REFERENCES}

Alam, M., K. I. Han, D. H. Lee, J. H. Ha, and J. J. Kim. 2012. Estimation of effective population size in the Sapsaree: a Korean native dog (Canis familiaris). Asian-Aust. J. Anim. Sci. 25:1063-1072.

Allen, Jr. S. K., and S. L. Downing. 1986. Performance of triploid pacific oyster, Crassostrea gigas. I. Survival, growth, glycogen content, and sexual maturation in yearlings. J. Exp. Mar. Bil. Ecol. 102:197-208

Beaumont, A. R., and J. E. Fairbrother. 1991. Ploidy manipulation in molluscan shellfish: a review. J. Shellfish Res. 10:1-18.

Chambers, G. K. and E. S. MacAvoy. 2000. Microsatellites: consensus and controversy. Comp. Biochem. Physiol. Part B Biochem. Mol. Biol. 126:455-476.

Dadi, H., J.-J. Kim, D. Yoon, and K. S. Kim. 2012a. Evaluation of single nucleotide polymorphisms (SNPs) genotyped by the Illumina bovine SNP50K in cattle focusing on Hanwoo breed. Asian-Aust. J. Anim. Sci. 25:28-32.

Dadi, H., S.-H. Lee, K. S. Jung, J. W. Choi, M.-S. Ko, Y.-J. Han, J.-J. Kim, and K. S. Kim. 2012b. Effect of population reduction on mtDNA diversity and demographic history of Korean cattle populatioins. Asian-Aust. J. Anim. Sci. 25:12231228.

Durand, P., K. T. Wada, and A. Komaru. 1990. Triploidy induction by caffeine-heat shock treatments in the Japanese pearl oyster Pinctada fucata martensii. Nippon Suisan Gakkaishi 56:14231425.

Gardner, C., G. B. Maguire, and G. N. Kent. 1996. Studies on triploid oysters in Australia: VII. Assessment of two methods for determining triploidy: adductor muscle diameter, and nuclear size. J. Shellfish. Res. 15:609-615.
Ge'rard, A., Y. Naciri, J. M. Peignon, C. Ledu, P. Phelipot, C. Noiret, I. Peudenire, and H. Grizel. 1994. Image analysis: a new method for estimating triploidy in commercial bivalves. Aquacult. Fish. Manage. 25:697-708.

Guo. X., and S. K. Allen, Jr. 1994a. Sex determination and polyploid gigantism in the dwarf-surf clam, Mulinia lateralis Say. Genetics 138:1199-1206.

Guo. X., and S. K. Allen, Jr. 1994b. Reproductive potential and genetics of triploid Pacific oysters, Crassostrea gigas (Thunberg). Biol. Bull. 187:309-318.

Guo. X., and S. K. Allen, Jr. 1994c. Viable tetraploids in the Pacific oyster (Crassostrea gigas Thunberg) produced by inhibiting polar body I in eggs from triploids. Mol. Mar. Biol. Biotechnol. 3:42-50.

Guo, X., G. A. DeBrosse, and S. K. Allen, Jr. 1996. All-triploid Pacific oysters (Crassostrea gigas Thunberg) produced by mating tetraploids and diploids. Aquaculture 142:149-161.

Guo, X. 1999. Superior growth as a general feature of triploid shellfish: evidence and possible causes. J. Shellfish. Res. 18: 266-267.

Harrell, R. M., W. van Heukelem, and J. H. Kerby. 1995. Triploid induction validation techniques: a comparison of karyotyping, flow cytometry, particle size analysis and staining nucleolar organizer regions. Aquaculture 137:159-160.

Li, G., S. Hubert, K. Bucklin, C. Ribes, and D. Hedgecock. 2003. Characterization of 79 microsatellite DNA markers in the Pacific oyster Crassostrea gigas. Mol. Ecol. Notes 3:228-232.

Magoulas, A., B. Gjetvaj, V. Terzoglou, and E. Zouros. 1998. Three polymorphic microsatellites in the Japanese oyster, Crassostrea gigas (Thunberg). Anim. Genet. 29:69-70.

McCombie, H., C. Ledu, P. Phelipot, S. Lapegue, and P. Boudry. 2005. A complementary method for production of tetraploid Crassostrea gigas using crosses between diploids and tetraploids with cytochalasin $\mathrm{b}$ treatments. Mar. Biotechnol. 7:318-330.

Nell, J. A. 2002. Farming triploid oysters. Aquaculture 210:69-88.

Piferrer, F., A. Beaumont, J. C. Falguiere, M. Flajshans, P. Haffray, and L. Colombo. 2009. Polyploid fish and shellfish; production, biology and applications to aquaculture for performance improvement and genetic containment. Aquaculture 293:125-156.

Sekino, M., M. Hamaguchi, F. Aranishi, and K. Okoshi. 2003. Development of novel microsatellite DNA markers from the Pacific oyster Crassostrea gigas. Mar. Biotechnol. 5:227-233.

Slabbert, R., N. Prins, and D. Brink. 2010. A microsatellite panel for triploid verification in the abalone Haliotis midae. Afr. J. Mar. Sci. 32:259-264. 